IMECE2011-64235

\title{
A SUPPORT TOOL FOR TEACHING GRAFCET: ENGINEERING STUDENTS' PERCEPTIONS
}

\author{
Celina P. Leão \\ Department of Production and Systems \\ Engineering School, University of Minho, \\ Guimarães, Portugal
}

\author{
Filomena O. Soares \\ Department of Industrial Electronics, \\ Engineering School, University of \\ Minho, Guimarães, Portugal
}

\author{
José Machado \\ Mechanical Engineering \\ Department/CT2M Research Centre, \\ Engineering School, University of \\ Minho, Guimarães, Portugal
}

\author{
P.B. de Moura Oliveira \\ Department of Engineering, Science and \\ Technology School, University of \\ Trás-os-Montes and Alto Douro, \\ Vila Real, Portugal
}

\author{
J. Boaventura Cunha \\ Department of Engineering, Science and \\ Technology School, University of \\ Trás-os-Montes and Alto Douro, \\ Vila Real, Portugal
}

\begin{abstract}
Modeling discrete event systems with sequential behavior can be a very hard and complex task. Some formalisms are used in this context, such as: Petri Nets, Statecharts, Finite automata, Grafcet and others. Among these, Grafcet seems to be a good choice because it is easy: to learn, to understand and to use. Teaching Grafcet is then relevant within engineering courses concerned with Industrial Automation.

A virtual laboratory, e-GRAFCET, developed and first tested in UTAD University; it is a new, easy-to-use multimedia e-educational tool to support the self-learning process of Grafcet. This paper, reports a study of e-GRAFCET use by the students of University of Minho. A questionnaire was prepared and students asked to fulfill it in a volunteer basis. The results were statistically analyzed and the scores compared. The overall objective is to understand how the tool helps students in their study, and consequently improve their learning off Grafcet, independently of their engineering background.
\end{abstract}

\section{INTRODUCTION}

Modeling discrete event systems with sequential behavior is a main subject related with Automation and Mechatronics fields. Grafcet (IEC, 2000) is a formalism which presents some advantages over other methods, such as Petri Nets (David and Alla, 1992), Statecharts (Harel, 1987), Timed Automata (Mealy, 1955), (Moore, 1956) among others. Indeed it is easy to use and understand, due to its graphical formalism with syntax and semantics well defined. Moreover, it has been the main inspiration of a major PLC (Programmable Logic Controllers) standardized languages (IEC, 1998) named as SFC (Sequential Function Chart).

Sometimes, Grafcet from IEC 60848 and SFC from IEC 61131-3 are mixed and confused as being the same. However, in reality they comprise quite different concepts: the first is a specification formalism and the second is a PLC programming language, although the idea behind the first one led to the development of the second one.

Teaching Automation concepts, particularly in modeling discrete sequential systems, Grafcet is widely used due to its simplicity to produce programs when PLCs allow direct use of SFC programming. Indeed, some PLC manufacturers incorporate SFC as a programming language. As mentioned previously, SFC programming language has been inspired on Grafcet formalism proposed by French Association for Economical and Technical Cybernetics (AFCET) in 1977 (IEC, 2000). Grafcet is a specification formalism for the functional description used to describe the deterministic behavior of the sequential part of an automated system (Matias et al., 2010). Teaching Grafcet is relevant within engineering courses concerned with Industrial Automation. That is the case of Mechanical and Industrial Electronics Engineering courses and their related programs.

The Bologna declaration changed the teaching model followed within Universities courses. The current education system requires students to play a more active role within the teaching/learning process (Leão et al., 2007). Following this trend, using multimedia technologies together with classical teaching methodologies constitutes a great improvement in the 
teaching/learning process of discrete sequential systems behavior modeling.

In this context, e-GRAFCET (http://al20905.com.sapo.pt/) is a new and easy-to-use multimedia e-educational tool to supporting the self-learning process of Grafcet (Matias et al., 2010). The student can access e-GRAFCET by the Internet when and where he/she pleases, resulting in a teaching/learning process more dynamic and challenging (McCray, 2000). eGRAFCET is a complement tool to the face-to-face teaching in classroom environment. The structure, graphical components and page contents were designed in order to keep e-GRAFCET simple to use and functional to maintain user's interest.

In a previous work (Matias et al., 2010), e-GRAFCET applicability as an educational tool was analyzed. Students of Industrial Automation subject, from Electrical and Computers Engineering MSc, and of Automation and Control subject, from Energy Engineering and Rehabilitation Engineering BEng, were asked to fill out a questionnaire. These two courses are from the UTAD University. The students' feedback motivated to make public the e-GRAFCET educational tool to other Portuguese Universities and within other engineering courses.

This virtual laboratory was presented to students of University of Minho, in the Curricular Units (CU) Automation, from the 3rd year of Mechanical Engineering Master Course and Process Control and Automation, from the 3rd year of Engineering and Industrial Management Master Course. eGRAFCET served as a complement to traditional classes. A questionnaire was prepared and students were asked to fulfill on a volunteer basis.

The questionnaire is divided into three main parts: (1) student identification (course, gender, age, computer use habits, and personal motivation), (2) technical skills, (3) soft skills; ending with an open question where the student could identify and described any errors that may have found.

Several answers were statistically analyzed and the scores compared in order to understand how the tool helps students' study and consequently improve in their learning on Grafcet Automation subject, independently of the engineering background.

\section{GRAFCET FORMALISM: A BRIEF OVERVIEW}

Concerning formalisms which specify discrete event systems behavior, Grafcet is one of the most important: easy to use and to understand by industrial technicians.

Several tools have been developed in this context, not only because Grafcet is a strong formalism in this domain, but also because of its similarities with the SFC programming language (IEC, 1993) for PLCs. Sometimes Grafcet and SFC concepts are mixed in the developed simulation tools and software, because the above mentioned similarities.

Some examples of those tools are:

- Automgen (Automgen, 2006), which is used in teaching, at the secondary school level, to learn automation in industry, for applications development. It is a very userfriendly software;
- Grafcet 2D (Grafcet2D, 2011), which is considered as a simple, yet reliable, and helpful application that can simulate any Grafcet specifying any automation system behavior;

- jGrafcet (jGrafcet, 2011), aims to supply a framework to help the definition of structures and simulation of Grafcet models. In the first project stage, the model representation and basic mechanisms of interpretation are defined. The second stage objective is to supply a visualization layer, which facilitates the creation and maintenance of graphical models. The project is also intended to supply a core of classes with small footprint, aiming at the use of embedded systems. This tool has been developed using Java language environment;

- EdiTSAB (EdiTSAB, 2011), is a tool for edition of Grafcet and electrical, pneumatics and hydraulic schemes;

- IsaGRAF (IsaGRAF, 2011), is a tool based on the internationally recognized industrial standard for industrial automation control languages, the IEC 611313 ;

- Automation Studio (AStudio, 2004), allows simulating complex systems plants connected with Grafcet/SFC controller program, by using internal variable connections;

- Dymola (Dymola, 2006), offers the possibility of using Modelica library Stategraphs to simulate a hybrid controller behavior. This state graphs library has been developed considering the main advantages of Grafcet and Statecharts.

e-GRAFCET tool has some characteristics which makes it quite a different compared to the above mentioned softwares and tools, to know:

- A free access tool. More attractive for users (students) as there is no commercial purposes;

- It is used based only in the Grafcet formalism (and not on the SFC programming language). This makes the tool more powerful since Grafcet is much more complex than SFC programming language;

- It can be used, almost directly, as main basis for PLC programming. If the PLC does not allow SFC as programming language, it can be translated to Ladder programming language, using translation algebraic equations (Machado et al., 2011).

These characteristics can be seen as advantages of this tool relatively to other mentioned tools.

\section{E-GRAFCET LABORATORY}

The e-GRAFCET was designed as a simple tool to be functionally used. While e-GRAFCET is not a PLC programming tool it can be used to derive PLC programs. It is organized accordingly to the following main sections:

i) Elementary notions

ii) Structures 
iii) Examples

iv) Assessment tests

As stated by its name, the elementary notions, section i) presents the basic elements of Grafcet, such as syntax and evolution rules. Section iv) allows users to perform a simple test assessment, which are randomly generated from a database questions. Sections ii) and iii) are explained below.

Section ii) Structures. This section is organized in two subsections: Elementary and Advanced Structures. The Elementary Structures covers the following topics:

- Selection of alternative sequences also known as OR divergence.

- The OR convergence of alternative sequences;

- Activation of parallel sequences also known as AND divergence.

- The synchronization of parallel sequences also known as the AND convergence.

The former structures are presented also in the context of:

- Interpreted parallelism, in which a number of sequences can be activated simultaneously, determined by the interpretation of the transitions conditions.

- Structural parallelism, in which a number of sequences can be activated simultaneously determined by one transition condition and the GRAFCET structure.

- Backward skip, when a certain sequence is to be repeated while a transition condition is fulfilled.

- Steps skip, allowing jumping over or to skip several steps in a sequence, if a transition condition is fulfilled.

The Elementary Structures subsection also includes topics related with Grafcet actions, namely regarding the continuous and stored types. All types of action are illustrated with animated examples, allowing visualizing the Grafcet evolution.

The Advanced Structure subsection concerns some complementary Grafcet structures proposed over the years, namely:

- Source and pit steps

- Source and pit transitions

- Macro-steps

- Time-dependent transitions

Section iii) Examples. e-GRAFCET includes several wellknown didactic controller logic modeling examples covering the main Grafcet structures:

- Cycle of a single sequence.

- Interpreted parallelism.

- Structured parallelism.

- Shared resource.

- Priorities to access shared resources.

Each example (see Fig. 1) presents an animation of the system to be controlled, the Grafcet model and PLC inputs/outputs logical state, which can be monitored throughout the simulation. While visualizing the animation, the student can open and use a help frame which explains the example details.

\section{CYCLE OF A SINGLE SEQUENCE - 4}
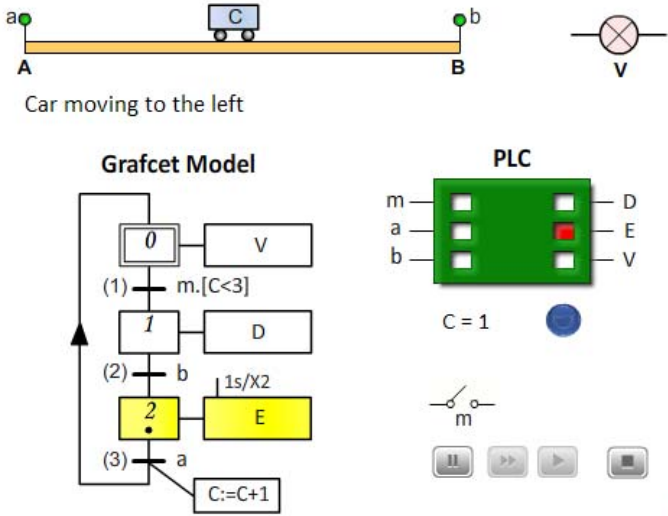

E-GRAFCET

Figure 1. Illustration of a single sequence cycle.

Fig. 2 illustrates an example that represents a common resource shared by two users. In this case the resource is a rail track (DC) shared by two cars (C1 and C2), exclusively. This means that just one car can be in the shared track.

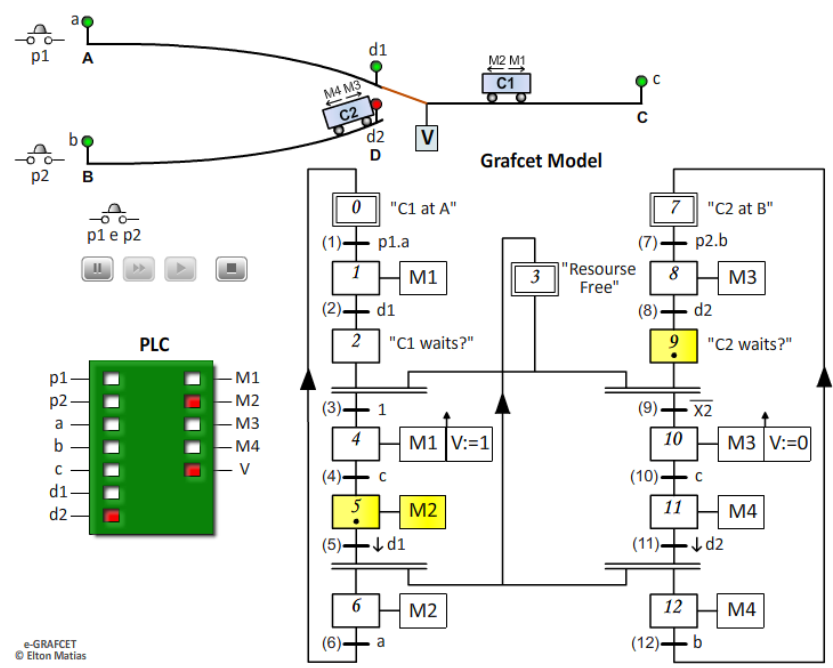

Figure 2. Access to shared resource controlled by a semaphore structure.

In the case that both cars arrive at the same time to point $\mathrm{D}$ (d1 or d2) only one is allowed to continue to the shared track. In this case priority is given to $\mathrm{C} 1$. The access to the shared resource is managed by using a structure known as semaphore. When the initial step 3 is active, it means that the shared resource is free to be used by either car.

Fig. 3 shows a variant of the example presented in Fig. 2 in which access to the common resource is performed alternately by the two cars. 


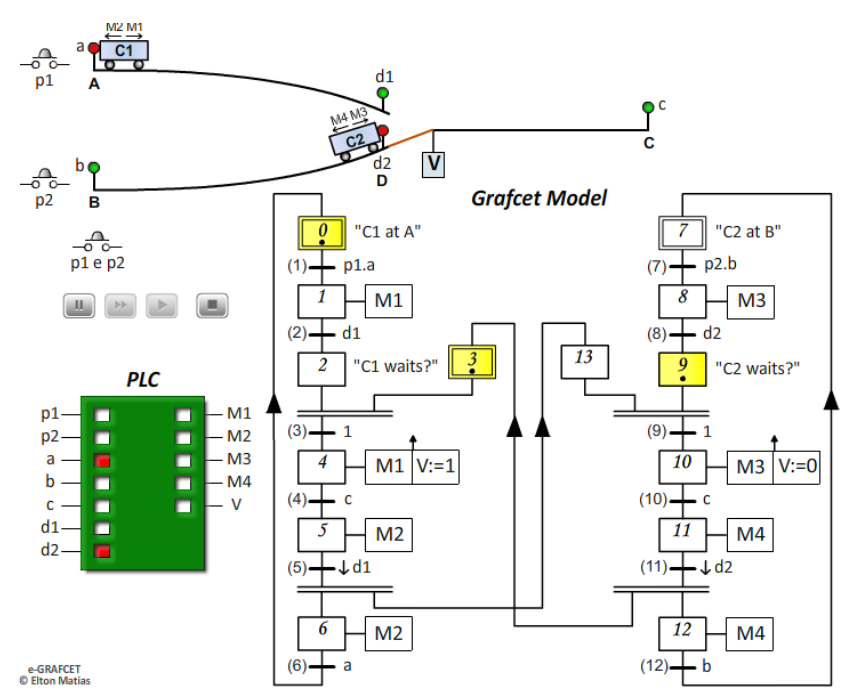

Figure 3. Access to a shared resource performed in an alternated way by the two cars.

As it can be seen from the Grafcet model shown in Fig. 3, the first car which can access the shared resource is C1, as defined by the initial step 3 . When car $\mathrm{C} 1$ releases the shared track, step 13 is initialized allowing car C2 to access the shared track.

\section{STUDENTS' CHARACTERIZATION}

Grafcet was tested in two Portuguese University schools and in different engineering courses: in UTAD University and in University of Minho.

e-GRAFCET has been used as an e-learning supporting tool in several courses in UTAD University since 2009. The courses were: Industrial Automation, MSc in Electrical and Computers Engineering, Automation and Control in the BEng in Energy Engineering and Rehabilitation Engineering. In a total of about 200 students who attend those courses. eGRAFCET can be used in classes to illustrate the simulation of discrete and sequential systems models and can be used on-line by students as a complementary learning tool. The feedback collected from students in classes is quite positive and encouraging. The animations allow students to simulate, step by step, the controllers' models discrete state evolution. This is very useful for students as their abstraction capability is not the same.

In order to disclose the tool e-GRAFCET as a learning tool, it was distributes in different higher education institutions in engineering. In particular the educational tool was presented to University of Minho, School of Engineering students and in the context of the CUs: Automation, from the $3^{\text {rd }}$ year of Mechanical Engineering Master Course (126 students) and Process Control and Automation, from the $3^{\text {rd }}$ year of Industrial Engineering and Management Master Course (49 students). It is worth mention that for the former students, Process Control and Automation CUs are perceived as apart from their main course plan. Generally these are subjects that students from these courses do not feel comfortable in studying. In all courses, e-
GRAFCET was a complement to traditional classes. In the CUs where the e-Grafcet was tested, some others formalisms for specification of discrete systems were also trained, namely: Petri Nets (Ordinary and Timed Petri Nets), Statecharts and Discrete and Timed Automata. However, by using e-GRAFCET environment, students were able to faster understand the formalism capabilities and potentialities.

At the end of the semester, students were asked to fulfill a questionnaire on a volunteer basis. Their feedback was registered and analyzed.

\section{STUDENTS' FINDINGS}

The opinions from students of University of Trás-osMontes and Alto Douro were published elsewhere (Matias et al., 2010). Nevertheless, summarizing the overall impression towards the tool, it is worth mentioning that:

- The degree of user satisfaction is particularly high;

- Concerning the graphical interface, Good (58\%) and Very Good (20\%) are the majority levels received, and the $22 \%$ achieved by Fair level indicates that there is still a margin for improvement;

- The tool functionality and quality of provided examples received also an expressive positive reply.

Overall, students considered e-GRAFCET as a user friendly, a well designed and a good support tool to be used within classes and in their individual learning process.

In order to investigate and to understand how e-GRAFCET is seen by students in different Universities and Engineering courses, a questionnaire was tested in University of Minho. The questionnaire was divided into five main parts: (1) student characterization (number, course identification, gender, age, students' habits and attitude characterization during the eGRAFCET access), (2) work environment identification (operating system and browsers identification), (3) technical skills, (4) soft skills and (5) two open questions where students can identify possible errors and write some suggestions. The statistical analysis of the questionnaires was done using SPSS software (Version 17.0) (SPSS, n.d.).

The questionnaires were sent by email to students and, after completed, sent back to the teacher also by email. Each questionnaire requires 5 to 10 minutes to be filled.

A group of 19 students responded to the challenge, with an average age of 22 years old, $16 \%$ were female and $84 \%$ were students from the third year of the Mechanical Engineering Course, the remaining students were from the third year Engineering and Industrial Management (both from University of Minho). It must be mentioned that $68.4 \%$ attended for the first time the classes of Automation. Most of the students identified Windows Seven and Vista (63.2 and 21.1\%, respectively) as the operation system used. Internet Explorer was identified by $36.8 \%$ of the students and Mozzila and Google Chrom by $31.6 \%$ each as the browsers used to access the e-GRAFCET.

It is important to state that for $89.5 \%$ of the students, it was the first time that they participated in this type of experience. 
The morning period $(9 \mathrm{H}-12 \mathrm{H})$ was identified only by $5.3 \%$ of the students as the period chosen to carry out the eGRAFCET experiences, being the night-time period $(18 \mathrm{H}-22 \mathrm{H})$ the most used. Students' home was the place by excellence to access the e-GRAFCET, 66.7\%. This gives the teacher an idea of hours that students preferred to study. The students were asked to use and test e-GRAFCET tool in the last two week of the semester.

The objective of this study is to measure students' degree of concordance concerning their motivation in using the eGRAFCET as an appropriate tool in their Automation learning process. In order to measure how students perceive the eGRAFCET as a tool in their technical skills development in Automation subject, they were asked to rate a set of 6 sentences, on a 1 to 5 scale (the highest value corresponds to a greater effectiveness). The analysis was focused on the average value obtained for the 6 sentences:

S1: e-GRAFCET general opinion.

S2: Available contents opinion.

S3: Graphical user interface rate.

S4: Page functionality rate.

S5: e-GRAFCET as a useful tool to support the learning process rate.

S6: Practical examples rate.

Fig. 4 illustrates the average value obtained for each of the 6 sentences above identified. The average evaluation was good (around 4). The values on the right hand-side of the vertical line indicate a positive attitude $(\geq 3)$. It must be pointed out that there is no significant difference between the means of the two courses of engineering students' opinion ( $p>0.05)$.

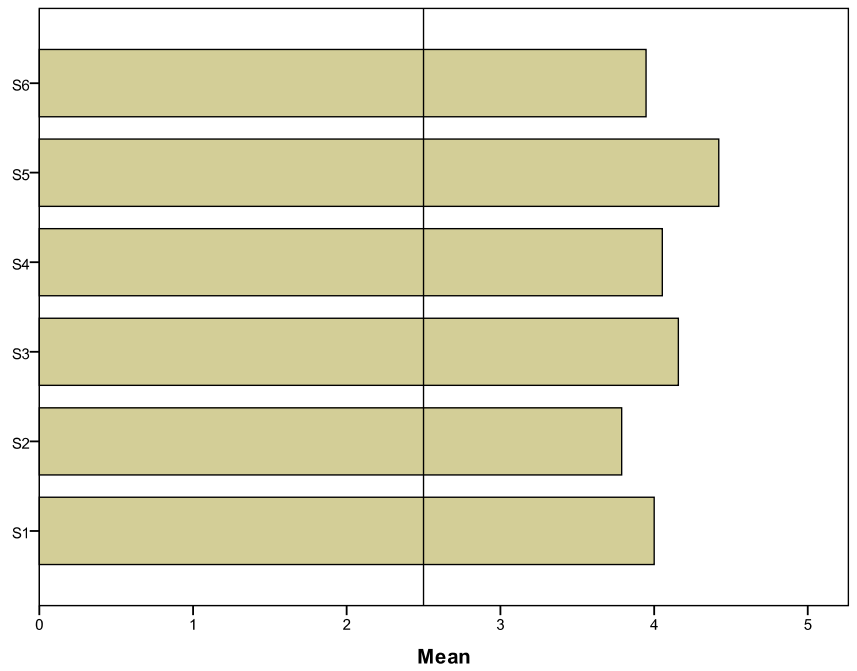

Figure 4. Average evaluation for the e-GRAFCET obtained for the 6 technical skills sentences.

When asked if the e-GRAFCET handouts are written clearly and concisely, $94.7 \%$ of the students answer in a positive way, and $100 \%$ considered that the flash animations represent well the various concepts of the Grafcet, allowing a better understanding of the method. e-GRAFCET is a user friendly software without difficulties to navigated in the platform (94.7\%). The flash animations with the representation of the Grafcet practical examples were identified by the students as the most positive aspect and the content most liked. For $84.2 \%$ of the students, the e-GRAFCET helps them in their Grafcet studies.

When asked if the e-GRAFCET support texts are written clearly and concisely, $94.7 \%$ of the students answer with a positive way, and $100 \%$ considered that the flash animations represent well the various concepts of the Grafcet, allowing a better understanding of the method. e-GRAFCET is a user friendly software without difficulty to navigated in the platform (94.7\%). The flash animations with the representation of the Grafcet, allowing to advance step by step, was the most positive aspect identified by students the content most liked. For $84.2 \%$ of the students, the e-GRAFCET helps them in their Grafcet studies.

Finally, students were asked about some soft skills learned, in accordance with the level of agreement: 1 - strongly disagree, 2 - disagree, 3 - undefined opinion, 4 - agree, 5 completely agree. The student chooses only one option in each item. The analysis was focused on the average value obtained for the 3 items considering that e-GRAFECT allows students:

I1: to encourage collaborative work.

I2: to stimulate their intellectual curiosity.

I3: to provide knowledge to their field of study.

Fig. 5 illustrates the average value obtained for each analyzed item. The average evaluation was positive (higher than 3) for all the considered items, transmitting a positive opinion towards the development and use of remote laboratories to promote the learning process. For the soft skills there is also no significant difference between the means of the two course of engineering students' opinion ( $\mathrm{p}>0.05$ ).

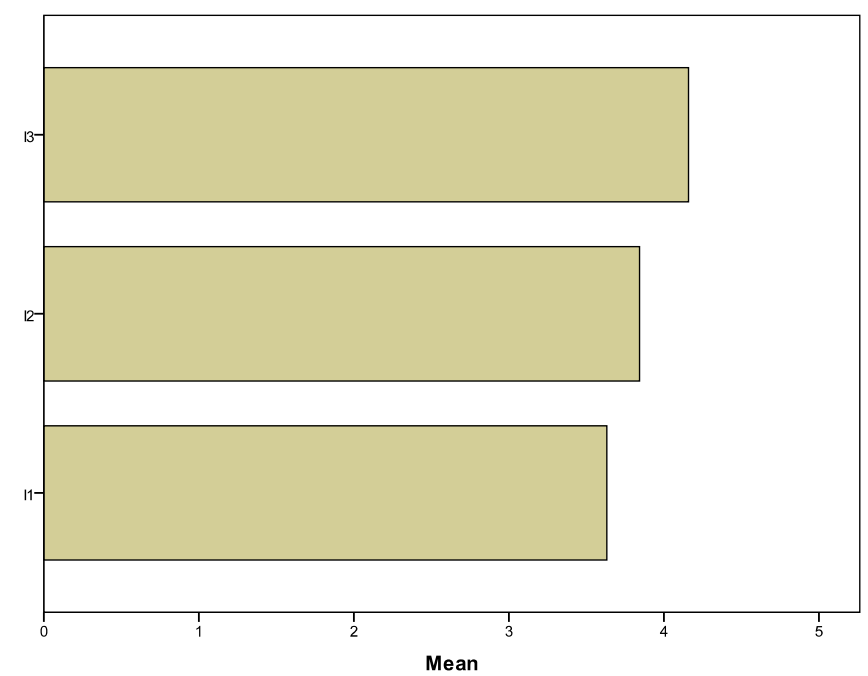

Figure 5. Average evaluation obtained for the 3 Automation learning process Soft skills items. 


\section{CONCLUSIONS}

Grafcet is an important subject taught in Industrial Automation courses. Following the new teaching/learning methodologies trends, Grafcet is an interesting field to implement multimedia tools to improve students' related knowledge..All the subjects within e-GRAFCET are illustrated with case-study animations and corresponding Grafcet evolution. The tool includes on-line knowledge evaluation tests allowing students to answer some simple questions.

e-GRAFCET was first evaluated at University of Trás-osMontes and Alto Douro. The general output from students was highly positive, confirming that the tool allowed them to improve their learning in Grafcet.

This first positive feedback allowed us to test e-GRAFCET in a different University and in distinct engineering courses. Last semester the tool was used a complement to traditional classes in University of Minho in the Curricular Units: Automation, from the 3rd year of Mechanical Engineering Master Course and Process Control and Automation, from the 3rd year of Industrial Engineering and Management Master Course. Students were asked to fulfill a questionnaire on a volunteer basis.

By using basic statistical concepts, it was possible to understand how students see the use of the e-GRAFCET in their teaching/learning methodologies in the Automation areas.

The overall impression of the tool is quite positive. Nevertheless, it is worth registering the small number of fulfilled questionnaires. Bologna brought a need for changing the teaching/learning process. But, it is the authors' believe that students (in general terms) are not yet complete available for those up-to-date methodologies.

\section{ACKNOWLEDGMENTS}

The authors are grateful to Portuguese Research Centers Algoritmi and CT2M for financial support. The authors are also grateful to the students that participated in this project.

\section{REFERENCES}

Automgen, (2006). Available: http://louispayen.apinc.org/ ressources/automgen/, accessed on May, $23^{\text {rd }} 2011$.

AStudio (2004). Available: http://www.automation studio. com/, accessed on May, $23^{\text {rd }} 2011$.
David, R. and H. Alla (1992). Petri Net and Grafcet: Tools for modelling discrete event systems. Prentice Hall.

Dymola, (2006). Available: http://www.3ds.com/products/ catia/portfolio/dymola, accessed on May, $23^{\text {rd }} 2011$.

EdiTSAB (2011). Available: http://log.editsab. pagespersoorange.fr/ , accessed on May, $23^{\text {rd }} 2011$.

Harel D. (1987). Statecharts: A Visual Formalism for Complex Systems. Science of Computer Programming 8 (1987) pp. 231-274.

IEC (2000). International Electrotechnical Commission, Langue de spécification GRAFCET pour diagrammes fonctionnels en séquence, 2 ed., CEI60848.

IEC (1998). Programmable Controllers - Programming languages, CEI 61131-3.

Grafcet2D (2011). Available: http://www.softpedia.com/ downloadTag/GRAFCET+2D, accessed on May, $23^{\text {rd }} 2011$.

jGrafcet (2011). Available: https://www.ohloh.net/p/ jgrafcet, accessed on May, $23^{\text {rd }} 2011$.

Leão, C.P., Silva, P.M., Oliveira, P.C., Carvalho, N.C., Soares, F.O. (2007), Learning automation by doing it - a case study, In: ICEE -International Conference of Engineering Education, 6pp.

Machado J., Seabra E., Campos J., Soares F., Leão C, (2011). Safe controllers design for industrial automation systems. Computers \& Industrial Engineering 60 (2011) 635653

Mealy, G.H. (1955). A Method to Synthesizing Sequential Circuits.Bell Systems Technical Journal. pp. 1045-1079.

Moore E.F. (1956). Gedanken-experiments on Sequential Machines. Automata Studies, Annals of Mathematical Studies, 34, 129-153. Princeton University Press, Princeton, N.J.

Moreno, S., Peulot, E. (1998). Le Grafcet, Conception Implementation dans les Automate Programmables Industriels. Educa Livre, Paris.

Matias, E.R., Moura Oliveira, P.B., Boaventura, J.C., Solteiro Pires, E.J., Soares, F., (2010) e-GRAFCET: A Multimedia Educational Teaching Tool, Controlo'2010, 9th Portuguese Conference on Automatic Control, September 2010, Coimbra, Portugal, 6pp.

Matias, E.R, Moura Oliveira, P.B., Boaventura, J. C., (2009) e-GRAFCET, http://al20905.com.sapo.pt

SPSS an IBM Company (n.d.), SPSS 17.0. Available: http://www.spss.com/, accessed in March 2011. 